\title{
Effects of Alloying Additions and Material Microstructure on the Accuracy of the Predictive Law of Creep Crack Growth for W-Strengthened 9-12\% Cr Ferritic Heat-Resistant Steel*
}

\author{
Ryuji Sugiura ${ }^{1}$, A. Toshimitsu Yokobori Jr. ${ }^{1}$, Shinjyu Takamori ${ }^{1}$, Masaaki Tabuchi ${ }^{2}$, \\ Akio Fuji ${ }^{3}$, Mitsuo Yoda ${ }^{4}$, Kenichi Kobayashi ${ }^{5}$ and Takeo Yokobori ${ }^{6}$ \\ ${ }^{1}$ Graduate School of Engineering, Tohoku University, Sendai 980-8579, Japan \\ ${ }^{2}$ National Institute for Materials Science, Tsukuba 305-0047, Japan \\ ${ }^{3}$ Metallurgy Department, Research Institute, Ishikawajima-Harima Heavy Industries Co., Ltd., Tokyo 135-0061, Japan \\ ${ }^{4}$ Graduate School of Engineering, Nihon University, Koriyama 963-1165, Japan \\ ${ }^{5}$ Department of Urban Environmental Systems, Faculty of Engineering, Chiba University, Chiba 263-8522, Japan \\ ${ }^{6}$ School of Engineering and Science, Teikyo University, Utsunomiya 320-8551, Japan
}

The life of creep crack growth for $\mathrm{W}$-strengthened $9-12 \% \mathrm{Cr}$ steel is sensitive to the alloying additions and to differences in material microstructure, such as lath martensitic structure and grain size caused by differences in cooling rates in the steel ingots during the manufacturing process, which results in the large scatter of experimental data from the law of creep crack growth life. In the present study, creep crack growth tests were conducted using W-strengthened $9-12 \% \mathrm{Cr}$ steels with various contents of alloying additions and the dimensions of micro-nano structures. The effects of the composition of alloying additions and material microstructures on the life of creep crack growth for W-strengthened 9-12\%Cr steel were clarified. [doi:10.2320/matertrans.MRA2007112]

(Received May 15, 2007; Accepted August 28, 2007; Published October 25, 2007)

Keywords: tungsten strengthened 9-12\%chromium ferritic heat-resistant steel, molybdenum equivalence (molybdenum\% $+1 / 2$ tungsten $\%)$, lath martensitic structure, grain size, creep, crack growth

\section{Introduction}

The research on heat-resistant steels for the application of fuel-fired power plants has progressed remarkably for the past 50 years, resulting in the improvement of electrical efficiency for coal-fired fossil fuel power plants. ${ }^{1,2)}$ At the present time, there are programs to develop ultra-supercritical plants aimed at operations under steam temperature and pressure conditions of $600 / 650^{\circ} \mathrm{C}$ and $32 \mathrm{MPa}$. The $\mathrm{W}$ strengthened $9-12 \% \mathrm{Cr}$ ferritic heat-resistant steel has been developed as boiler and turbine rotor materials for this ultrasupercritical plant. ${ }^{1-7)}$

Until now, the fundamental mechanical properties of the $\mathrm{W}$-strengthened 9-12\% Cr ferritic heat-resistant steels have been investigated by conducting Charpy impact tests, creep tests and tensile tests using smooth specimens. ${ }^{6,7)}$

However, when these materials are applied for practical component structures, there will be some possibilities of crack initiation and damage progression due to various applied loading factors. Therefore, on the basis of the previously proposed predictive method of crack growth life ${ }^{8,9)}$ some of the present authors have derived laws of creep crack growth and its life for these materials by conducting creep crack growth tests. ${ }^{10-12)}$

However, the life of creep crack growth for W-strengthened $9-12 \% \mathrm{Cr}$ ferritic heat-resistant steel is sensitive to the alloying additions and to differences in material microstructure, such as lath martensitic structure and grain size caused by differences in cooling rates in the steel ingots during the manufacturing process. ${ }^{13)}$ This resulted in an

*This Paper was Originally Published in Japanese in J. Japan Inst. Metals 70 (2006) 452-460. increase in the sensitivity of creep crack growth resistance to material microstructure. This naturally causes an increase in data scatter from mechanical laws for the life of creep crack growth under high-temperature creep conditions.

Therefore, clarification of the effects of the composition of alloying additions and material microstructure on the law of creep crack growth life is considered to contribute to the improvement of the high-accuracy prediction of the life of creep crack growth.

In the present study, creep crack growth tests were conducted using $\mathrm{W}$-strengthened $9-12 \% \mathrm{Cr}$ ferritic heatresistant steel with various contents of alloying additions and microstructural dimensions. The effects of the composition of alloying additions and material structures on the life of creep crack growth for $\mathrm{W}$-strengthened $9-12 \% \mathrm{Cr}$ ferritic heatresistant steel were clarified. Furthermore, the degree of improvement on the predictive accuracy of creep crack growth life was discussed.

\section{Experimental Procedure}

\subsection{Materials and specimens}

The material used is $\mathrm{W}$-strengthened $9-12 \% \mathrm{Cr}$ ferritic heat-resistant steel with the Mo equivalent ([Mo] $+1 / 2[\mathrm{~W}])$ (mass\%) value kept at $1.5 \%$. ${ }^{4}$ Six kinds of materials with variation in $\mathrm{W}$ and Mo contents under the condition of $1.5 \%$ Mo equivalence were prepared for creep crack growth tests.

W-strengthened $9-12 \% \mathrm{Cr}$ ferritic heat-resistant steel, developed by substituting part of the Mo content with W, has been reported to have excellent characteristics of creep strength and ductility when the value of the Mo equivalent $([\mathrm{Mo}]+1 / 2[\mathrm{~W}])(\operatorname{mass} \%)$ takes the value of $\left.1.5 \% .^{4}\right)$

Depending on the operating temperature, under the 
Table 1 Chemical composition of $9-12 \% \mathrm{Cr}$ steel in mass $\%$.

\begin{tabular}{cllllllll}
\hline Specimen No. & $\mathrm{C}$ & $\mathrm{Cr}$ & $\mathrm{Mo}$ & $\mathrm{W}$ & $\mathrm{Nb}$ & $\mathrm{V}$ & $\mathrm{Co}$ & $\mathrm{Mo}+\mathrm{W} / 2$ \\
\hline 1 & 0.09 & 10.89 & 0.17 & 2.61 & 0.06 & 0.2 & 2.52 & 1.48 \\
2 & 0.09 & 11 & 0.23 & 2.66 & 0.07 & 0.22 & 2.53 & 1.56 \\
3 & 0.11 & 10.7 & 0.22 & 2.54 & 0.07 & 0.22 & 2.63 & 1.49 \\
4 & 0.1 & 10.21 & 0.14 & 2.51 & 0.07 & 0.21 & 2.44 & 1.4 \\
5 & 0.101 & 8.96 & 0.48 & 1.94 & 0.0065 & 0.201 & - & 1.45 \\
6 & 0.11 & 11.08 & 0.16 & 2.62 & 0.05 & 0.2 & 2.93 & 1.47 \\
\hline
\end{tabular}

Table 2 Mechanical properties of $9-12 \% \mathrm{Cr}$ steel.

\begin{tabular}{ccccc}
\hline Specimen No. & $\begin{array}{c}\text { Temp. } \\
\left({ }^{\circ} \mathrm{C}\right)\end{array}$ & $\begin{array}{c}\text { UTS } \\
(\mathrm{MPa})\end{array}$ & $\begin{array}{c}\text { Yield stress } \\
(\mathrm{MPa})\end{array}$ & $\begin{array}{c}\text { Elongation } \\
(\%)\end{array}$ \\
\hline 1 & - & - & - & - \\
\hline \multirow{2}{*}{2} & R.T & 847 & 712 & 20 \\
\cline { 2 - 5 } & 650 & 373 & 325 & 27.9 \\
\hline \multirow{2}{*}{3} & 20 & 853 & 705 & 19.3 \\
\cline { 2 - 5 } & 650 & 386 & 294 & 31.7 \\
\hline \multirow{2}{*}{5} & - & - & - & -18.7 \\
\hline & 600 & 440 & 716 & 22.8 \\
\hline \multirow{2}{*}{6} & 20 & 941 & 809 & 17.8 \\
\hline & 600 & 544 & 449 & 21.6 \\
\hline & 650 & 456 & 360 & 27.1 \\
\hline
\end{tabular}

constant Mo equivalence of $1.5 \%,([\mathrm{~W}] /\{[\mathrm{Mo}]+1 / 2[\mathrm{~W}]\})$ $(\operatorname{mass} \%)$ and $([\mathrm{Mo}] /\{[\mathrm{Mo}]+1 / 2[\mathrm{~W}]\})(\operatorname{mass} \%)$ are designed to take higher values in the regions of higher and lower temperatures, respectively. ${ }^{4)}$

9 and $12 \% \mathrm{Cr}$ ferritic heat-resistant steels have been developed for the application to the components of boiler and turbine rotors at the temperatures of 593 and $650^{\circ} \mathrm{C}$, respectively.

The chemical composition, mechanical properties and manufacturing processes of the materials are shown in
Table 3 Ingot weight, remelting method and heat treatment condition of each specimen.

\begin{tabular}{ccccc}
\hline Specimen No. & $\begin{array}{c}\text { Ingot } \\
\text { weight }\end{array}$ & $\begin{array}{c}\text { Remelting } \\
\text { method }\end{array}$ & Heat treatment condition \\
\hline 1 & 20 tons & ESR & O.Q.: $1050^{\circ} \mathrm{C}$ & A.C.: $700^{\circ} \mathrm{C}$ \\
2 & 20 tons & ESR & O.Q.: $1050^{\circ} \mathrm{C}$ & A.C.: $720^{\circ} \mathrm{C}$ \\
3 & $50 \mathrm{~kg}$ & VAR & O.Q.: $1050^{\circ} \mathrm{C}$ & A.C.: $720^{\circ} \mathrm{C}$ \\
4 & 80 tons & ESR & O.Q.: $1050^{\circ} \mathrm{C}$ & A.C.: $700^{\circ} \mathrm{C}$ \\
5 & Lab. scale & - & O.Q.: $1070^{\circ} \mathrm{C}$ & A.C.: $780^{\circ} \mathrm{C}$ \\
6 & Lab. scale & - & O.Q.: $1100^{\circ} \mathrm{C}$ & A.C.: $750^{\circ} \mathrm{C}$ \\
\hline
\end{tabular}

ESR: Electro-slag remelting, VAR: Vacuum-arc remelting, O.Q.: Oilquenched, A.C.: Air-cooled
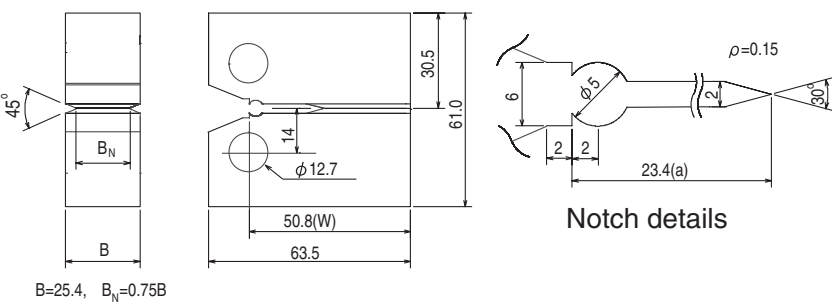

Fig. 1 Geometry and size of a CT specimen. ${ }^{14)}$

Tables 1, 2 and 3, respectively.

On the basis of ASTM E1457-00, the specimen used is manufactured into a standardized CT specimen for creep crack growth tests as shown in Fig. 1.14)

\subsection{Test method and conditions}

Creep crack growth tests were performed using a lever arm creep testing machine (RT-30) manufactured by TOSHIN KOGYO.

The crack length was measured by an electrical potential method. ${ }^{15,16)}$ An electrical current is applied to the specimen and the value of the electric potential drop is measured. The crack length is usually calculated using Johnson's equation given by eq. (1). ${ }^{15,16)}$

$$
a=\frac{2 W}{\pi} \cos ^{-1}\left[\frac{\cosh (\pi y / 2 W)}{\cosh \left\{\left(u / u_{0}\right) \cosh ^{-1}\left\langle\cosh (\pi y / 2 W) / \cos \left(\pi a_{0} / 2 W\right)\right\rangle\right\}}\right]
$$

where $a$ is the length of the crack (mm), $a_{0}$ is the initial crack length $(\mathrm{mm}), y$ is half the distance between the output terminals $(\mathrm{mm}), W$ is the width of the specimen $(\mathrm{mm}), u_{0}$ is the initial voltage $(\mu \mathrm{V})$, and $u$ is the actual value of the potential $(\mu \mathrm{V})$.

Creep crack growth tests were carried out under constant load and temperature conditions of $311.8 \mathrm{MPa}$ and $650^{\circ} \mathrm{C}$. The test temperatures were kept at a specified value with a precision of $\pm 2{ }^{\circ} \mathrm{C}$.

The creep crack growth tests were conducted on the basis of ASTM E1457-00. ${ }^{14)}$

Creep fracture surfaces and material microstructures were observed using a laser scanning microscope of Type OLS1100 manufactured by SHIMADZU and an atomic force microscope of Type SPM-9500 manufactured by SHIMAD$\mathrm{ZU}$ in order to evaluate the structure on macro-, meso- and nano-scales.
The observations of material structures were carried out on tested specimens. Specimens of suitable size for AFM observation were cut from an area away from the damaged surface. They were mechanically polished and buff-finished to a mirror surface with $0.06 \mu \mathrm{m} \mathrm{Al}_{2} \mathrm{O}_{3}$ particles. Finally, the specimens were etched in a mixture of $\mathrm{FeCl}_{2}(10 \mathrm{~g}), \mathrm{HCl}$ (30 ml), and $\mathrm{H}_{2} \mathrm{O}(100 \mathrm{ml})$ to observe the material microstructures.

\section{Experimental Results}

\subsection{Scatter of experimental results caused by the dif- ferences in the alloying additions and material} structures

Values of the creep crack growth life of W-strengthened $12 \% \mathrm{Cr}$ ferritic heat-resistant steels with the Mo equivalence being constant at $1.5 \%$ were considered to have the same 


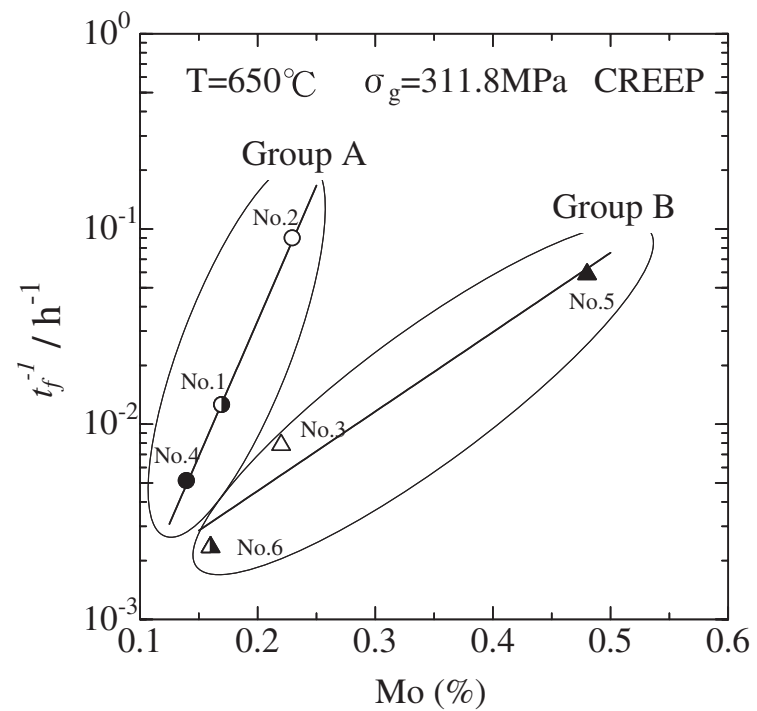

Fig. 2 Effect of the content of molybdenum on the life of creep crack growth.

characteristic under the same experimental conditions in terms of parameters such as applied loads, temperatures and specimen geometries.

However, in many cases, there are differences in the grain size and variation of $\mathrm{W}$ and Mo contents despite the similar conditions of heat treatments and Mo equivalence.

In the present study, scatter of the values of creep crack growth life caused by differences in the alloying additions and material microstructures for $\mathrm{W}$-strengthened $12 \% \mathrm{Cr}$ steels and also 9\% Cr steels were investigated.

Creep crack growth tests of $\mathrm{W}$-strengthened $9-12 \% \mathrm{Cr}$ steels were conducted for six samples of materials with various $\mathrm{W}$ and Mo contents under the conditions of $1.5 \% \mathrm{Mo}$ equivalence under the constant load of $311.8 \mathrm{MPa}$ at a temperature of $650^{\circ} \mathrm{C}$, as shown in Table 1 .

The experimental results of creep crack growth life show scatter in the range from 11.2 to $426 \mathrm{~h}$ and the standard deviation from the average value was more than $100 \%$.

The reasons for scatter in the experimental data are considered to be the differences in the composition of alloy additions and material microstructures due to the differences in cooling rates induced by the effect of different masses of steel ingots.

In this section, the effects of the alloy additions and the variations of material microstructures on the law of creep crack growth life are investigated.

These results will promote the development of the control technique for material structure that will enable us to accurately predict crack growth life and will contribute to the realization of high accuracy in the law for predicting the creep crack growth life.

\subsection{Effect of alloy composition on the law of creep crack growth life}

In this section, the effect of alloy composition on the law of creep crack growth life is investigated.

In order to determine the dominant effect of the alloy addition on creep crack growth life, the correlation between the life of creep crack growth obtained from experimental

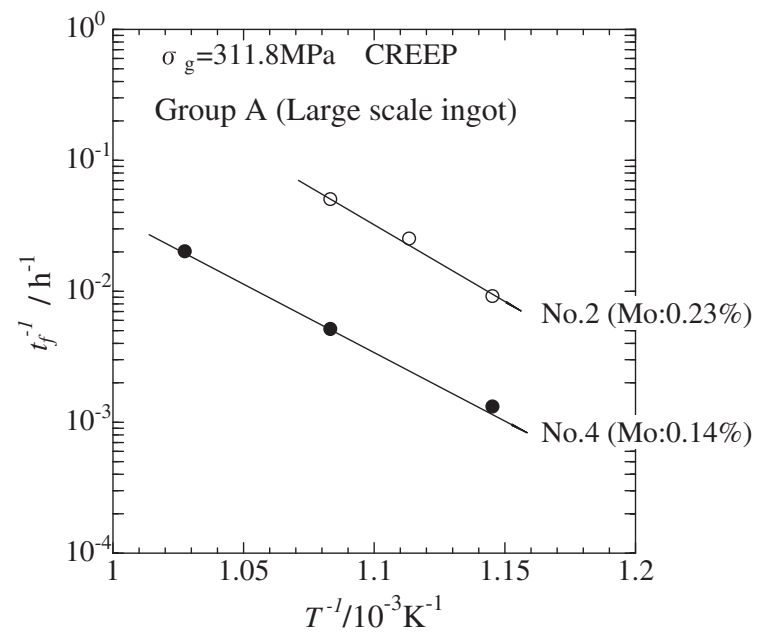

Fig. 3 Relationship between the life of creep crack growth and absolute temperature (Large-scale ingot, group A).

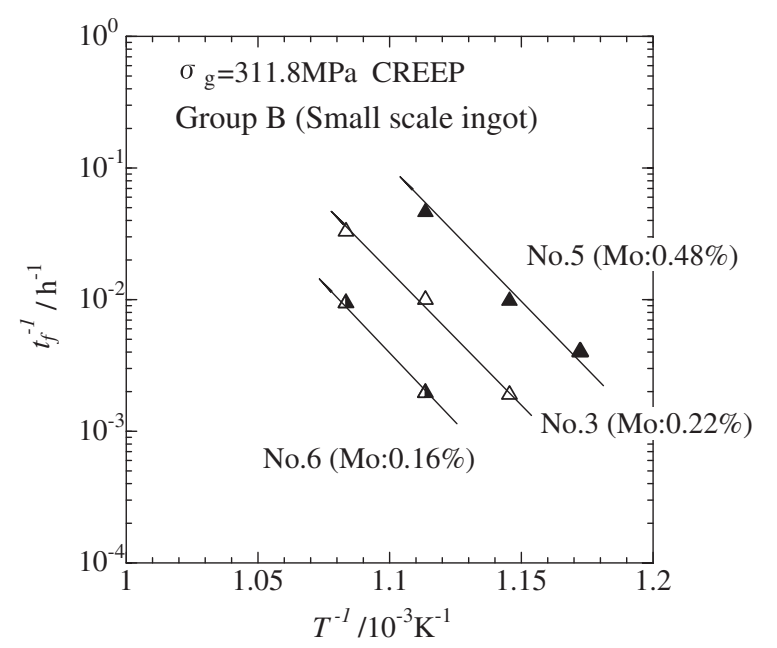

Fig. 4 Relationship between the life of creep crack growth and absolute temperature (Small-scale ingot, group B).

results and the amount of alloy addition was investigated. The results showed that the alloy addition that causes the greatest change in the law of creep crack growth is the absolute amount of Mo under the condition of $1.5 \%$ Mo equivalence. The effect of the absolute amount of Mo is to give a linear change in the life of creep crack growth, as shown in Fig. 2.

Figure 2 shows that the data of the creep crack growth life are clearly classified into two groups denoted A and B. One is the group of data for specimens sampled from the large-scale ingot of 20 or 80 tons (Group A). The other is the group of data for specimens that are sampled from the small-scale ingot of $50 \mathrm{~kg}$ (Group B).

For the experimental results of each group, the characteristic of the creep crack growth life shows a linear relationship against the absolute amount of Mo. In order to clarify the effect of Mo content on the life of creep crack growth, the relationship between the inverse value of the creep crack growth life, $1 / t_{\mathrm{f}}$, and the inverse value of the absolute temperature, $1 / T$, are shown in Figs. 3 and 4 for groups $A$ and $\mathrm{B}$, respectively. 


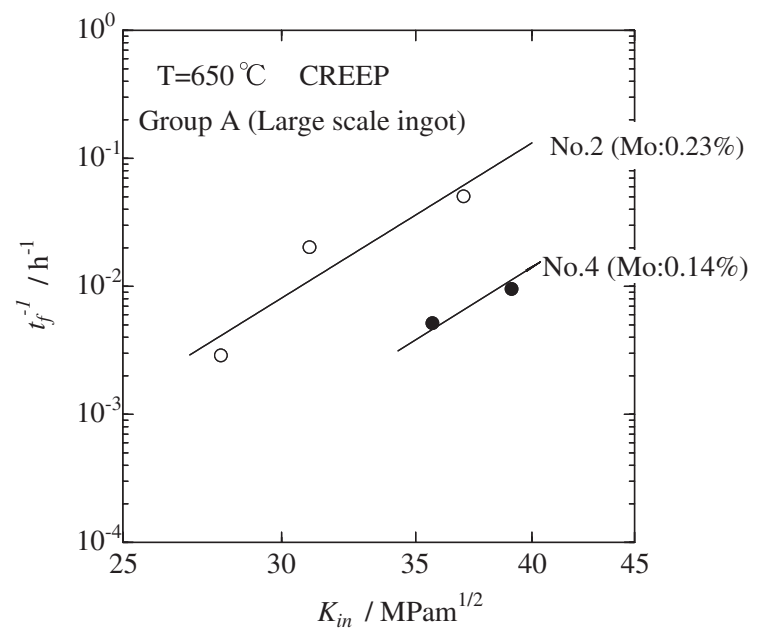

Fig. 5 Relationship between the life of creep crack growth and the initial stress intensity factor (Large-scale ingot, group A).

Within a group (A or B), the gradient of the linear relationships between $1 / t_{\mathrm{f}}$ and $1 / T$ was found to be constant, as shown in Figs. 3 and 4 for groups A and B, respectively. Therefore, the effect of Mo content on the life of creep crack growth is to cause a parallel shift in the linear relationship between $1 / t_{\mathrm{f}}$ and $1 / T$. These characteristics show that since the activation energy of the crack growth life corresponds to the gradient of the linear relationship between $\ln 1 / t_{\mathrm{f}}$ and $1 / T$, the numerical value of the activation energy of creep crack growth life is found not to be influenced by the Mo content, and the effect of Mo content on the law of creep crack growth life causes the proportional change of the creep crack growth life. The numerical values of the activation energy for groups A and B are 225 and $434 \mathrm{~kJ} / \mathrm{mol}$, respectively.

The relationships between the inverse value of the creep crack growth life, $1 / t_{\mathrm{f}}$, and the initial stress intensity factor, $K_{\text {in }}$, are shown in Figs. 5 and 6 for groups $\mathrm{A}$ and B, respectively.

Linear relationships between $1 / t_{\mathrm{f}}$ versus $K_{\text {in }}$ appear and they were found to shift in a parallel manner for different amounts of Mo. These characteristics show that the values of the exponent of the initial stress intensity factor are not influenced by Mo content for groups A and B. The values of the exponent of $K_{\text {in }}$ are 10 and 6.0 for groups A and B, respectively.

From the results mentioned above, the laws of creep crack growth life have unique characteristic values of the activation energy and power coefficient of initial stress intensity factor for groups A and B. That is, the effect of Mo content on the law for predicting the life of creep crack growth shows the proportional effect on the law.

Therefore, for each group of $\mathrm{A}$ and $\mathrm{B}$, the law for predicting the life of creep crack growth, which incorporates the effect of Mo content, is derived and the degree of improvement in the predictive accuracy of creep crack growth life is discussed.

For creep-brittle materials, the equation of creep crack growth rate is defined by eq. (2) on the basis of the $Q^{*}$ concept: ${ }^{8,9)}$

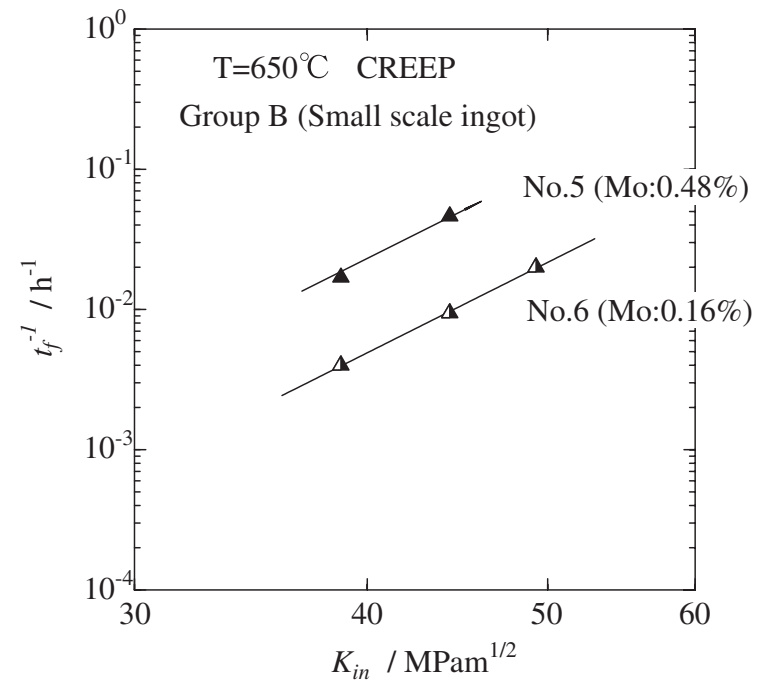

Fig. 6 Relationship between the life of creep crack growth and the initial stress intensity factor (Small-scale ingot, group B).

$$
\frac{d a}{d t}=A \exp \left(Q^{*}\right)=A K_{\mathrm{in}}^{n} \exp \left(-\frac{\Delta H_{g}}{R T}\right)
$$

where $A$ is a constant, $Q^{*}$ is the $Q^{*}$ parameter, $K_{\text {in }}$ is the initial stress intensity factor $\left(\mathrm{MPa} \mathrm{m}^{1 / 2}\right), n$ is the exponent of $K_{\text {in }}$, $\Delta H g$ is the activation energy $(\mathrm{kJ} / \mathrm{mol}), R$ is the gas constant $(=8.3145 \mathrm{~J} / \mathrm{Kmol}$ ) and $T$ is the absolute temperature $(\mathrm{K})$.

The life of creep crack growth $t_{\mathrm{f}}$ is obtained by integrating eq. (2) from $a_{i}$ to $a_{f}$, as given by eq. (3):

$$
\begin{aligned}
t_{\mathrm{f}} & =\int_{0}^{t_{\mathrm{f}}} d t=\int_{a_{i}}^{a_{f}} \frac{d a}{A \exp \left(Q^{*}\right)} \\
& =\frac{1}{A} \exp \left(-Q^{*}\right)\left(a_{f}-a_{i}\right)=\frac{1}{A^{*}} \exp \left(-Q^{*}\right)
\end{aligned}
$$

where $t_{\mathrm{f}}$ is the life of creep crack growth (h), $a_{i}$ is the initial crack length $(\mathrm{mm}), a_{f}$ is the final crack length $(\mathrm{mm})$ and $A^{*}$ is a constant $\left[=A /\left(a_{f}-a_{i}\right)\right]$.

From eq. (3), the following equation is obtained:

$$
\frac{1}{t_{\mathrm{f}}}=A^{*} K_{\mathrm{in}}^{n} \exp \left(-\frac{\Delta H_{g}}{R T}\right) .
$$

On the basis of eq. (4), the law of creep crack growth life that incorporates the effect of Mo content is derived as shown in eqs. (5) and (6) for groups A and B, respectively.

Group A

$$
\begin{aligned}
\frac{1}{t_{\mathrm{f}}} & =f_{1}(M o \%) K_{\mathrm{in}}^{n} \exp \left(-\frac{\Delta H_{g}}{R T}\right) \\
& =f_{1}(M o \%) K_{\mathrm{in}}^{10.0} \exp \left(-\frac{225}{R T}\right)
\end{aligned}
$$

where $f_{1}(M o \%)=1.87 \times 10^{-20} \exp (32 \times M o \%)$ and $M o \%$ is the absolute amount of Mo.

Group B

$$
\begin{aligned}
\frac{1}{t_{\mathrm{f}}} & =f_{2}(M o \%) K_{\mathrm{in}}^{n} \exp \left(-\frac{\Delta H_{g}}{R T}\right) \\
& =f_{2}(M o \%) K_{\mathrm{in}}^{6.0} \exp \left(-\frac{434}{R T}\right)
\end{aligned}
$$

where $f_{2}(M o \%)=3.12 \times 10^{-13} \exp (9.55 \times M o \%)$. 


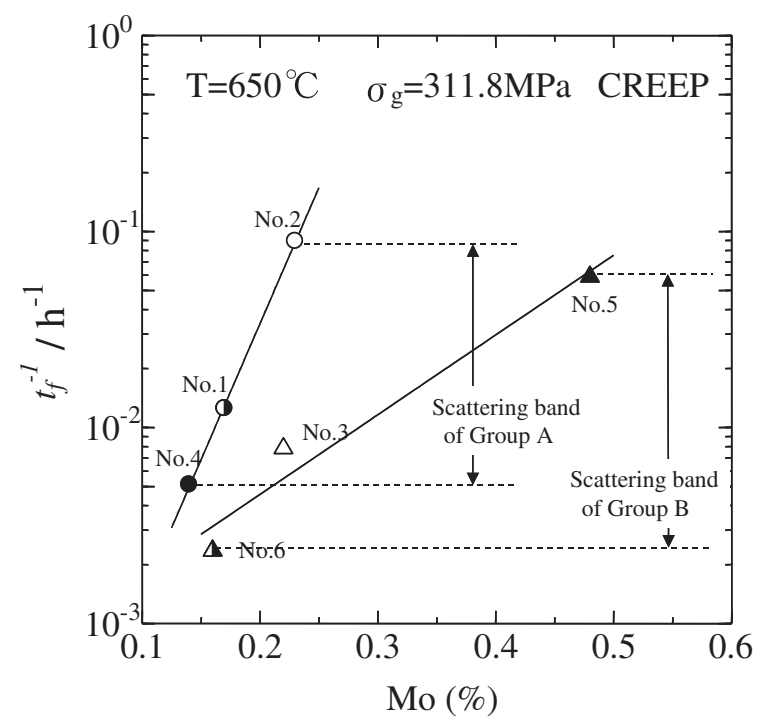

Fig. 7 Scatter of the creep crack growth life for groups A and B.

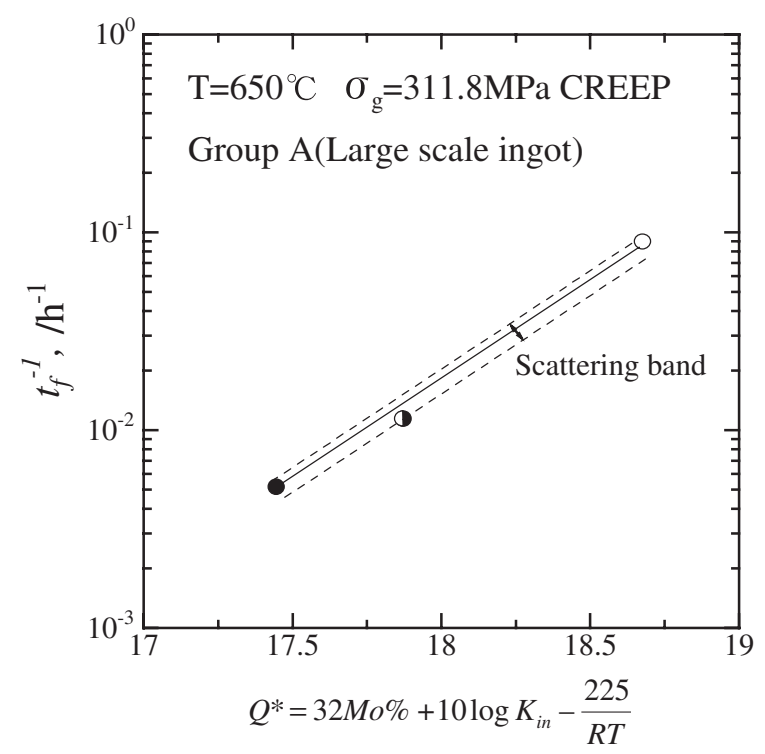

Fig. 8 Relationship between the life of creep crack growth and $Q^{*}$ parameter (Large-scale ingot: 20, 80 tons, group A).

In order to investigate the degree of improvement in the predictive accuracy of creep crack growth life given by eqs. (5) and (6), the $Q^{*}$ parameter is derived for each group of A and B to estimate the life of creep crack growth. This is defined in eq. (2). .8 )

For the large-scale ingot (Group A), the $Q^{*}$ parameter is derived on the basis of eq. (5). This is given by

$$
Q^{*}=32 M o \%+10 \log K_{\text {in }}-\frac{225}{R T} \text {. }
$$

The characteristics of the creep crack growth life for the large-scale ingot (Group A) are evaluated using this $Q^{*}$ parameter as shown in Fig. 8; they are compared with the scattering feature of crack growth life plotted against the absolute amount of Mo, as shown in Fig. 7.

This result shows that the accuracy of the prediction of creep crack growth life was improved and the data scatter decreased from $100 \%$ to $11 \%$ as shown in Figs. 7 and 8.

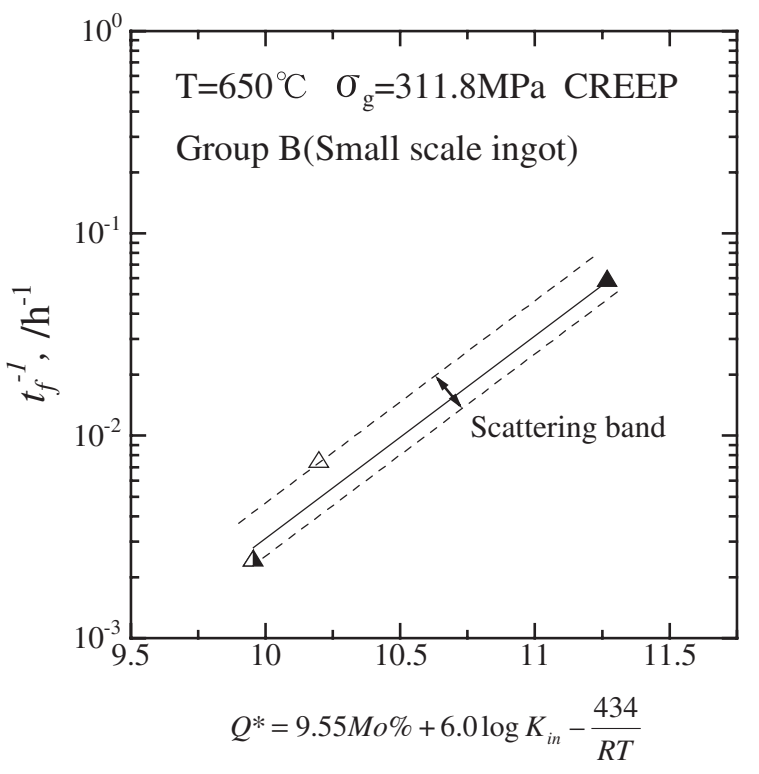

Fig. 9 Relationship between the life of creep crack growth and $Q^{*}$ parameter (Small-scale ingot: $50 \mathrm{~kg}$, group B).

For the small-scale ingot (Group B), the estimation of creep crack growth life is also conducted using the $Q^{*}$ parameter. The $Q^{*}$ parameter is derived on the basis of eq. (6). This is given in eq. (8).

$$
Q^{*}=9.55 M o \%+6.0 \log K_{\text {in }}-\frac{434}{R T}
$$

The creep crack growth life for the small-scale ingot (Group B) is plotted against the $Q^{*}$ parameter as shown in Fig. 9.

This result shows that the accuracy of the prediction of creep crack growth life was improved and the data scatter decreased from $100 \%$ to $17 \%$ as shown in Figs. 7 and 9.

The reason why the experimental data were divided into two groups, as shown in Fig. 2, is discussed in section 3.3.

\subsection{Investigation of the relationship between creep fracture mechanism and material microstructure by microscopic observation}

\subsubsection{Observation of creep fracture surface by laser scanning microscopy}

In the relationship between the absolute value of Mo content and the creep crack growth life shown in Fig. 2, the experimental data were found to be divided into groups A and B. Furthermore, the activation energy and power coefficient value of initial stress intensity factor in the law of the life of creep crack growth were found to be different between these two groups. Therefore, in this section, on the basis of metallographical investigation, the characterizations of the creep fracture surface are presented and the reason why the experimental characteristics were divided into groups A and $\mathrm{B}$ are clarified.

Three-dimensional representations of the creep fracture surface obtained by laser scanning microscopy for groups A (large-scale ingot: 20, 80 tons) and B (small-scale ingot: $50 \mathrm{~kg}$ ) are shown in Figs. 10 and 11, respectively.

The experimental results in Figs. 10 and 11 show that 

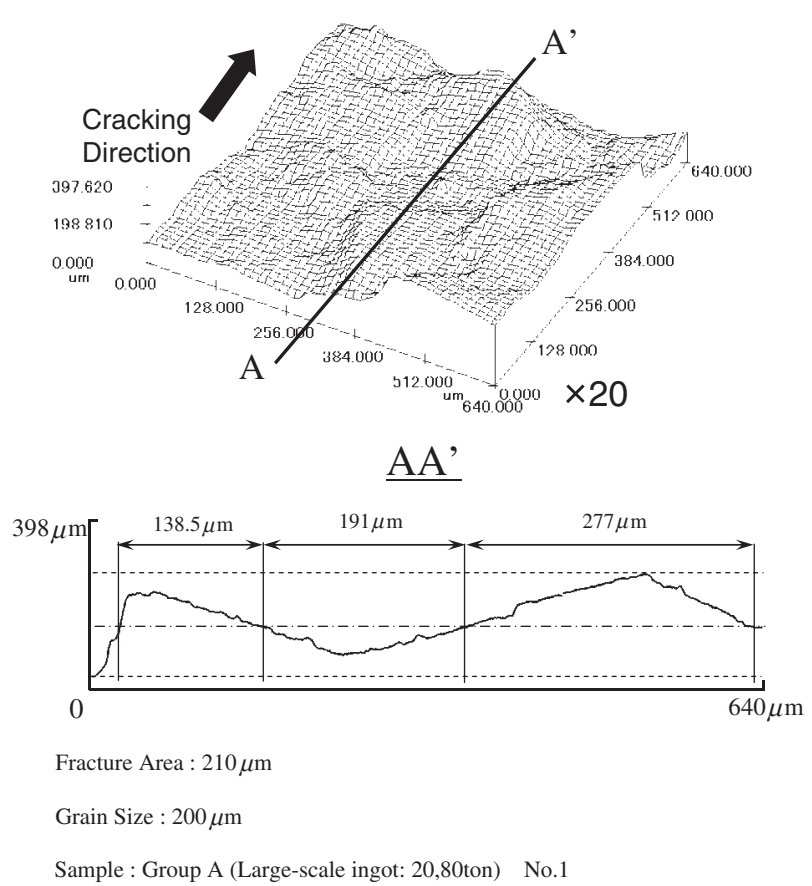

Fig. 10 Three-dimensional representation of creep fracture surface obtained by laser scanning microscopy [Group A (large-scale ingot) No. 1].

creep cracks of both groups $\mathrm{A}$ and $\mathrm{B}$ grew in a periodic convexo-concave manner. The length of periodic convexoconcave segments of the creep fracture surface was measured and quantitative characterization of the creep fracture surface was conducted. The measurement method of a segment is as follows. The base line was drawn at the level of the mean value of the maximum and minimum heights of the convexoconcave segment. The distance between the points of intersection of the base line and creep fracture surface was defined as the length of a segment. The length of this periodic convexo-concave segment unit was denoted as the fracture area (FA).

On the basis of the results in Fig. 10, the average length of the FA of the specimen of group A (No. 1) is found to be $210 \mu \mathrm{m}$. Since the grain size of this material is $200 \mu \mathrm{m}$, the FA is found to be almost equal to the grain size. Therefore, the mechanism of creep crack growth of the specimen of group A (No. 1) is considered to be intergranular cracking, which is also found for the other specimens of group A.

On the other hand, on the basis of the results in Fig. 11, the average length of the FA of the specimen of group B (No. 6) is found to be $945 \mu \mathrm{m}$. Since the grain size of this material is $30 \mu \mathrm{m}$, the average length of the FA is found to be larger than the grain size. Therefore, the morphology of the creep crack growth of the specimen of group B (No. 6) is considered to be composed of a characteristic FA beyond the scale of the grain size. These Fracture Areas are considered to be caused by the growth of branched creep cracks that are larger than the grain size induced by the constraint of intergranular cracking due to the strengthened mechanism such as a martensitic lath. Similar results are also found for the other specimens of group B.

From the experimental results mentioned above, it is considered that the scale of the FA on the creep crack growth fracture surface is the origin of the difference in the law of the
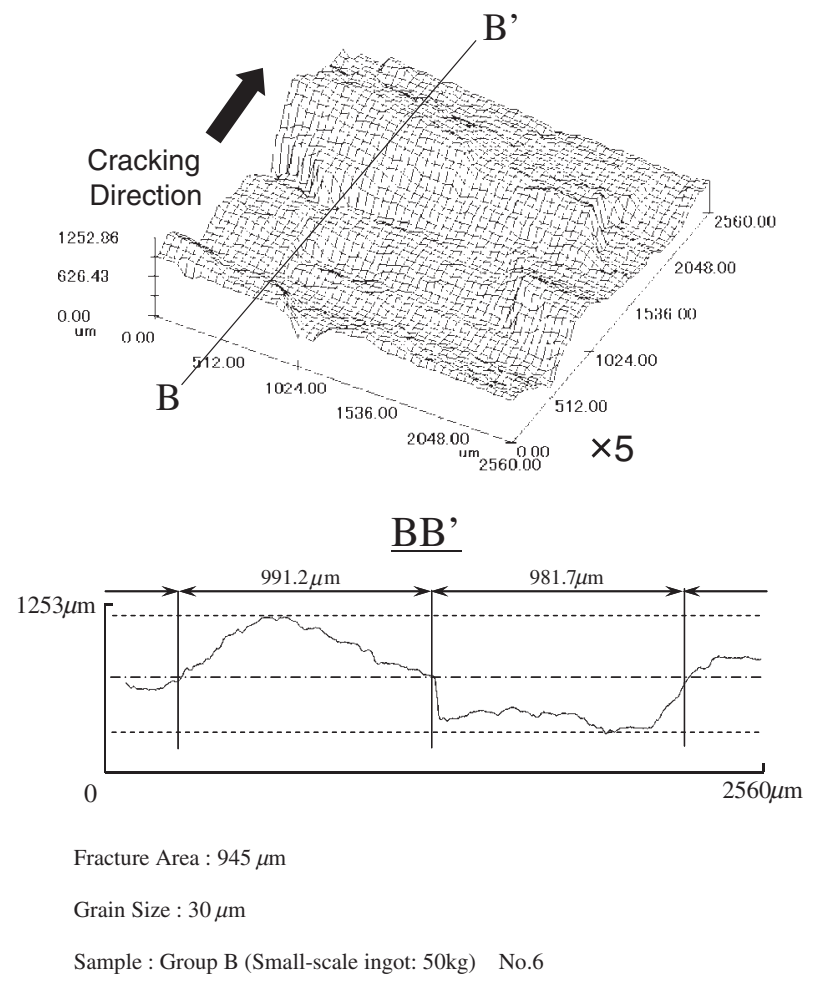

Fig. 11 Three-dimensional representation of creep fracture surface obtained by laser scanning microscopy [Group B (small-scale ingot) No. 6].

creep crack growth between groups A and B. Not only a difference in grain size but also a difference in fracture mechanism, such as intergranular cracking and the mechanism of FA beyond the grain size, exists between groups A and B. Correspondingly as is shown in section 3.2, the difference in activation energy $\Delta H g$ was found between groups A and B ( $\Delta H g$ for group A is $225 \mathrm{~kJ} / \mathrm{mol}$ and that for group $B$ is $434 \mathrm{~kJ} / \mathrm{mol}$ ). This may come from the effects of the grain size and the coarsening of the martensitic lath due to the difference in cooling rate during the manufacturing process of steel ingots that have different weight volumes. Therefore, in the next section, the effect of the scale of the lath martensitic structure on the life of creep crack growth is investigated.

\subsubsection{Observation of microstructure of material by AFM}

In the previous section, the difference in the laws for predicting the creep crack growth life between groups A and $\mathrm{B}$ caused by the differences in cooling rates during the manufacturing process of steel ingots that have different weight volumes is considered to appear not only in the grain size but also in the microstructure of materials such as martensitic lath. Therefore, on the basis of the method described in section 2.2, the tested specimens were polished and etched. The observations of microstructures were carried out using atomic force microscopy (AFM). The results were then related to the grain size.

Three-dimensional representations of material surfaces obtained by AFM for groups A (large-scale ingot: 20, 80 tons) and B (small-scale ingot: $50 \mathrm{~kg}$ ) are shown in Figs. 12 and 13 , respectively.

The experimental results in Figs. 12 and 13 show that 

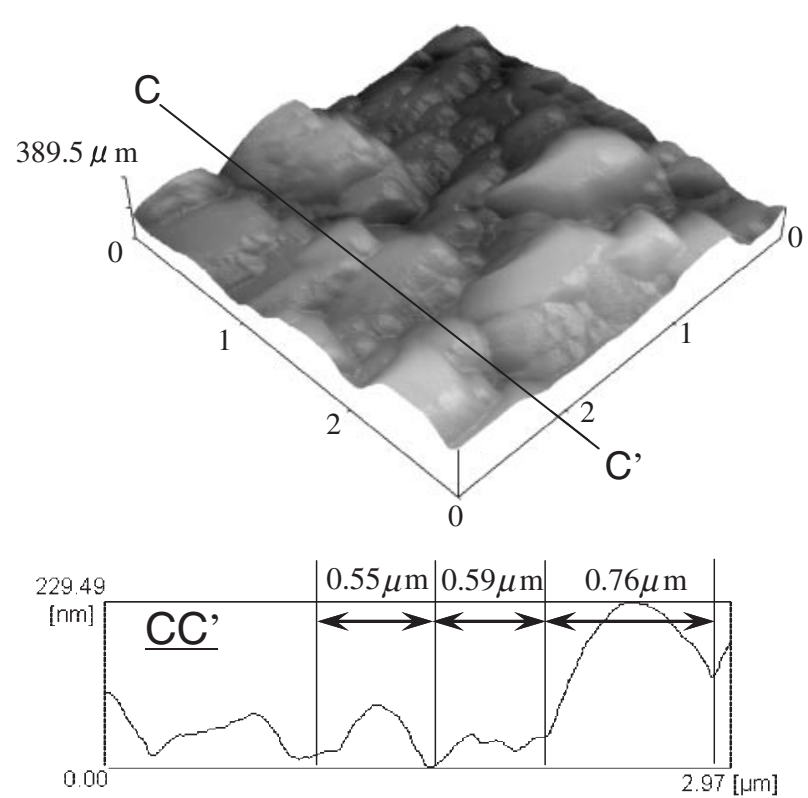

Length of 1 segment : $0.5 \sim 0.8 \mu \mathrm{m}$

Sample : Group A (Large-scale ingot: 20,80ton) No.1

Fig. 12 Three-dimensional representation of material surface obtained by AFM [Group A (large-scale ingot) No. 1].

material surfaces of both groups A and B also had a periodic convexo-concave manner. The length of the periodic convexo-concave segment of the material surface was found to be different between groups $\mathrm{A}$ and $\mathrm{B}$.

On the basis of the result in Fig. 12, the length of a segment for the specimen of group A (No. 1) was found to be $0.5 \sim 0.8 \mu \mathrm{m}$. On the other hand, on the basis of the result in Fig. 13, the length of a segment for the specimen of group B (No. 6) was found to be $0.25 \sim 0.42 \mu \mathrm{m}$. The length of a segment in Fig. 12 is found to be equal to the average width of a coarsened martensitic lath. The length of a segment in Fig. 13 is found to be equal to the width of noncoarsened martensitic lath. ${ }^{17)}$ Therefore, the difference in the experimental results mentioned above is considered to be related to the difference in the width of martensitic lath induced by the differences in the cooling rates during the manufacturing process of steel ingots that have different weight volumes. The relationship between the grain size and the width of martensitic lath is shown in Fig. 14. From the result in Fig. 14, the grain size and the width of martensitic lath are found to be well correlated (correlation coefficient value: $0.98)$.

The experimental results presented above show that the difference in the laws for predicting the creep crack growth life between groups $\mathrm{A}$ and $\mathrm{B}$ due to the differences in the cooling rates during the manufacturing process of steel ingots that have different weight volumes appears not only in the grain size but also in the martensitic-lath-strengthened structure.

These results suggest that measurement of the grain size or the width of martensitic lath enables us to clarify whether the fracture mechanism is dominated by the intergranular cracking (group A) or the mechanism of the FA (group B) where the scale is larger than the grain size.
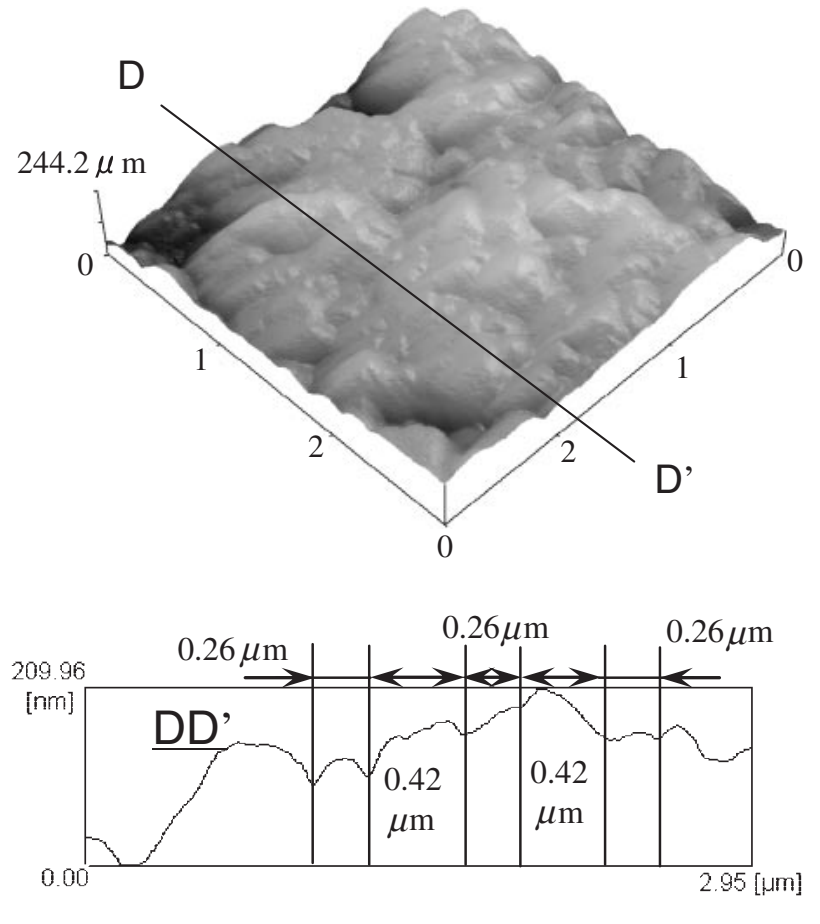

Length of 1 segment : $0.25 \sim 0.42 \mu \mathrm{m}$

Sample : Group B (Small-scale ingot: 50kg) No.6

Fig. 13 Three-dimensional representation of material surface obtained by AFM [Group B (small-scale ingot) No. 6].

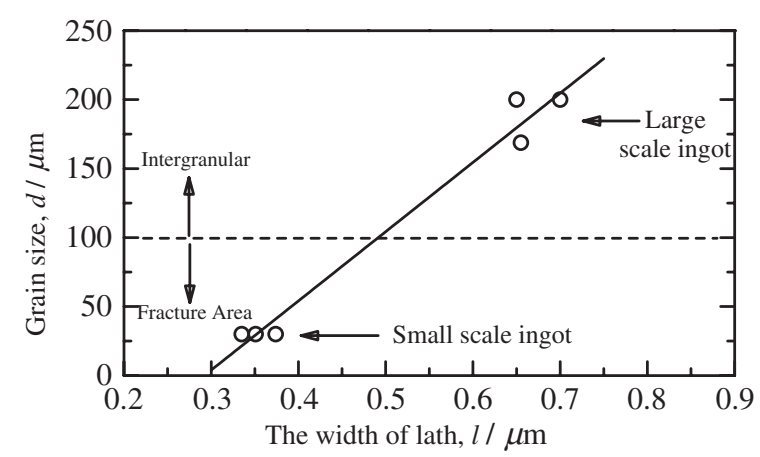

Fig. 14 Relationship between grain size and the width of lath.

On the basis of eqs. (5) and (6) in section 3.2, the law of creep crack growth life that incorporates the effect of Mo content and microstructure is given by

$$
\frac{1}{t_{\mathrm{f}}}=f_{3}\left(M o \%, d^{*}\right)\left(\frac{K_{\mathrm{in}}}{K_{\mathrm{i} 0}}\right)^{n\left(d^{*}\right)} \exp \left(-\frac{\Delta H_{g}\left(d^{*}\right)}{R T}\right),
$$

where $d^{*}=d / d_{0}\left(d\right.$ : grain size $\left.(\mu \mathrm{m}), d_{0}: 1 \mu \mathrm{m}\right), K_{\mathrm{i} 0}=1$ $\mathrm{MPa} \mathrm{m}^{1 / 2}$, and $f_{3}\left(M o \%, d^{*}\right), n\left(d^{*}\right)$ and $\Delta H_{g}\left(d^{*}\right)$ are given by eqs. (10), (11) and (12), respectively.

$$
\begin{aligned}
f_{3}\left(M o \%, d^{*}\right)= & \left(-1.83 \times 10^{-9} d^{*}+3.67 \times 10^{-13}\right) \\
& \times \exp \left\{\left(1.32 \times 10^{5} d^{*}+5.59\right) M o \%\right\} \\
n\left(d^{*}\right)= & 2.35 \times 10^{4} d^{*}+5.29 \\
\Delta H_{g}\left(d^{*}\right)= & 471-1.23 \times 10^{6} d^{*}
\end{aligned}
$$

On the basis of eq. (9), the $Q^{*}$ parameter is derived as 


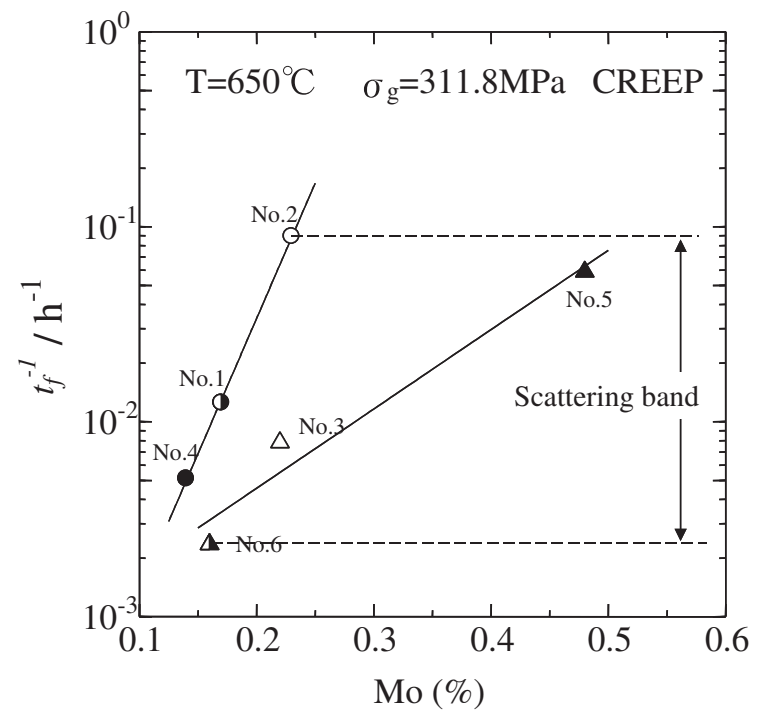

Fig. 15 Scatter of the creep crack growth life.

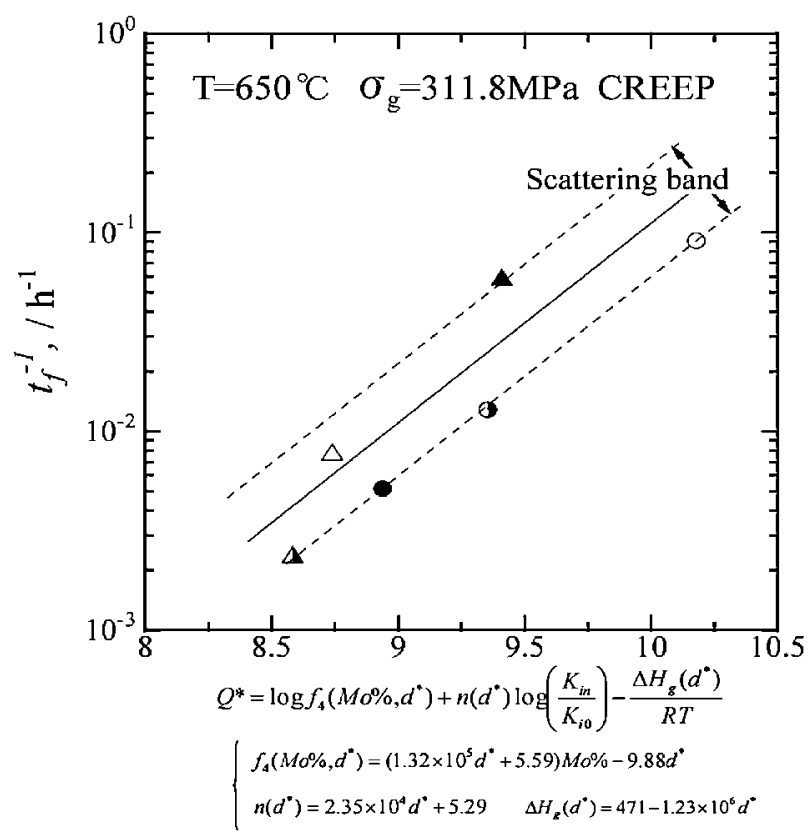

Fig. 16 Relationship between the life of creep crack growth and $Q^{*}$ parameter including data of groups $\mathrm{A}$ and $\mathrm{B}$.

$Q^{*}=\log f_{4}\left(M o \%, d^{*}\right)+n\left(d^{*}\right) \log \left(\frac{K_{\mathrm{in}}}{K_{\mathrm{i} 0}}\right)-\frac{\Delta H_{g}\left(d^{*}\right)}{R T}$,

where $f_{4}\left(M o \%, d^{*}\right)=\left(1.32 \times 10^{5} d^{*}+5.59\right) M o \%-9.88 d^{*}$.

The creep crack growth life both for the large-scale ingot (Group A) and the small-scale ingot (Group B) are plotted against the $Q^{*}$ parameter as shown in Fig. 16, and they are compared with the scattering feature of crack growth life plotted against the absolute amount of Mo, as shown in Fig. 15.

This result shows that the accuracy of the prediction of creep crack growth life is improved and the data scatter decreases from $100 \%$ to $30 \%$ as shown in Figs. 15 and 16. These results are considered to generally improve the accuracy of the predicted life of creep crack growth.

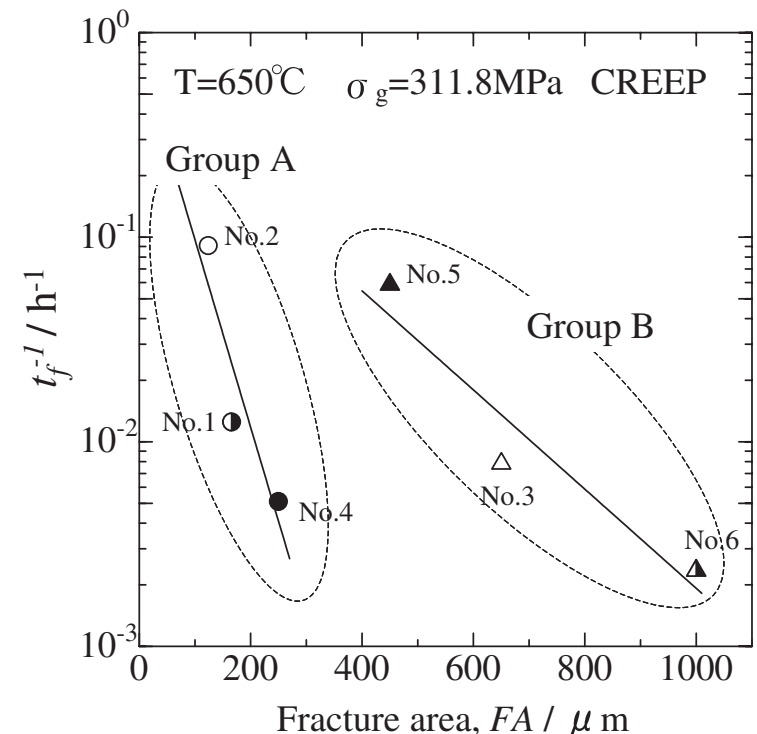

Fig. 17 Relationship between the life of creep crack growth and the FA.

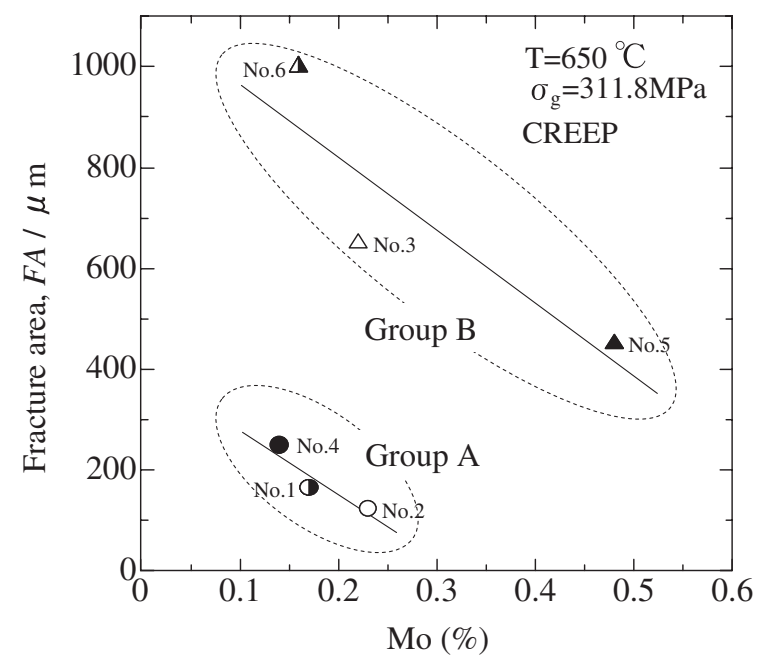

Fig. 18 Relationship between the FA and the content of molybdenum.

\subsubsection{Relationship between the life of creep crack growth, the absolute content of Mo and the fracture area (FA)}

The experimental results in the previous section showed that there are good correlations between the life of creep crack growth, the absolute content of Mo and the FA. In this section, these relationships are investigated in detail.

The relationship between the logarithmic value of $1 / t_{\mathrm{f}}$ and the FA is shown in Fig. 17 and the relationship between the FA and the absolute content of Mo is shown in Fig. 18. From the results in Figs. 17 and 18, the experimental relationships are found to be clearly classified into two groups of A and B, and there are good correlations in both groups, respectively.

The experimental results presented above indicate a good correlation between the life of creep crack growth, the absolute content of Mo and the FA. Furthermore, in order to conduct a detailed investigation of the correlation between them, the equation that is derived experimentally from Figs. 2 and 17 is compared with the equation that is derived from Fig. 18. 
From the results of Figs. 2 and 17, the expression for the relationship between the absolute content of Mo and the FA on the life of creep crack growth is given by

$$
\begin{aligned}
\frac{1}{t_{\mathrm{f}}} & =1.71 \times 10^{4} \exp (-31.9 \mathrm{Mo} \%) \\
& =1.24 \exp \left(2.11 \times 10^{-2} \mathrm{FA}\right)
\end{aligned}
$$

where $t_{\mathrm{f}}$ is the life of creep crack growth (h), Mo\% is the absolute content of Mo $(\%)$ and FA is the fracture area $(\mu \mathrm{m})$.

On the basis of eq. (14), the expression for the relationship between the absolute content of Mo and the FA is obtained as follows.

$$
F A=453-1514 M o \%
$$

On the other hand, from the result in Fig. 18, the direct expression for the relationship between the FA and the absolute content of Mo is given by eq. (16).

$$
F A=414-1300 M o \%
$$

Equation (15) is in quantitatively good agreement with eq. (16). These results indicate that the life of creep crack growth, the absolute content of Mo and the FA are well correlated.

\section{Conclusions}

Creep crack growth tests were conducted using Wstrengthened $9-12 \% \mathrm{Cr}$ steels with various contents of alloy additions and different microstructure dimensions. The effects of the composition of alloy additions and material microstructures on the life of creep crack growth for $\mathrm{W}$ strengthened $9-12 \% \mathrm{Cr}$ steel were clarified. Furthermore, the degree of improvement on the predictive accuracy of creep crack growth life was investigated. The following results were obtained.

(1) The life of creep crack growth for W-strengthened 9$12 \% \mathrm{Cr}$ steels was found to be sensitive to the absolute content of Mo under the condition of $1.5 \% \mathrm{Mo}$ equivalence. The effect of Mo content on the law for predicting the life of creep crack growth showed the proportional effect in the law.

(2) The differences in the cooling rates during the manufacturing process of steel ingots were found to affect not only the grain size but also the martensitic-lathstrengthened structure, which dominates quantitatively the activation energy and the values of the exponent of initial stress intensity factor in the law of creep crack growth life.

(3) The law for predicting the life of creep crack growth that incorporates the effect of the Mo content and the microstructure of the material was derived. Using this law for predicting the life of creep crack growth, the accuracy of the prediction of creep crack growth life was improved and the data scatter was reduced from $100 \%$ to $30 \%$. These results are considered to generally improve the accuracy of predicting the life of creep crack growth.

\section{Acknowledgement}

The authors acknowledge the 129 committee of the Japan Society for the Promotion of Science for supporting this research (Chairman: Prof. T. Yokobori). The authors thank the support of the 21st COE Program, "The Exploration of the Frontiers of Mechanical Science Based on Nanotechnology" from the Ministry of Education, Culture, Sports, Science and Technology. The authors also thank Dr. V. A. Yardley in Tohoku University for fruitful discussion.

\section{REFERENCES}

1) T. Fujita: Materia Japan 40 (2001) 938-942.

2) H. Yamada, Y. Hattori, N. Komai, T. Sato, H. Oohira and T. Yanagisawa: J. of Thermal and Nuclear Power 52 (2001) 1217-1231.

3) T. Fujita: Tetsu to Hagane 76 (1990) 1053-1059.

4) T. Fujita: J. of Thermal and Nuclear Power 42 (1991) 1485-1496.

5) F. Masuyama: Tetsu to Hagane 80 (1994) 587-592.

6) H. Naoi: Nippon Steel Technical Report 347 (1992) 27-31.

7) F. Abe and S. Nakazawa: Metall. Mater. Trans. A 23A (1992) 3025.

8) A. T. Yokobori Jr. and T. Yokobori: Advances in Fracture Research, Proc. ICF7, eds. K. Salama, K. Ravi-chandar, D. M. R. Taplin and P. Rama Rao, (Pergamon Press, 1989) pp. 1723-1735.

9) A. T. Yokobori Jr., T. Uesugi, T. Yokobori, A. Fuji, M. Kitagawa, I. Yamaya, M. Tabuchi and K. Yagi: J. Mater. Sci. 33 (1998) 15551562.

10) A. T. Yokobori Jr., S. Takamori, T. Yokobori, Y. Hasegawa, K. Kubota and K. Hidaka: Trans. The Annual Meeting of Japanese Society for Strength and Fracture of Materials, (2000) pp. 35-44.

11) M. Yoda, O. Yokota, R. Sugiura, A. T. Yokobori Jr. and T. Yokobori: Int. J. of Strength, Fracture and Complexity IOS Press 1 (2003) 167175.

12) O. Yokota, R. Sugiura, M. Yoda, A. T. Yokobori Jr. and T. Yokobori: Proc. ICF11, in the content of High Temperature \& Creep of CD rom, Ed. by A. Carpinteri et al., Turin, Italy, March 20-25th (2005).

13) T. Yokobori: Zairyo Kyodogaku, (GIHODO Pub., 1955) pp. 1-6. (In Japanese)

14) ASTM E1457-00. Standard Test Method of Measurement of Creep Crack Growth Rates in Metals, Annual Book of ASTM Standards, (2000) pp. 936-949.

15) H. H. Johnson: Materials Research and Standard 5 (1965) 442-445.

16) K. H. Schwalbe and D. Hellman: J. of Testing and Evaluation 9 (1980) 218-220.

17) T. Endo, F. Masuyama and K.-S. Park: Mater. Trans., JIM 44 (2003) 239-246. 